\title{
Research Paper: The Relationship between Demo- graphic, Health, Physical Fitness and Socioeconomic Determinants and Functional Performance of Elderly People
}

\author{
Mohamad Rostami $^{1}$, Zahra Mosallanezhad ${ }^{1 *}$, Afsun Nodehi Moghadam ${ }^{1}$, Enayat Allah Bakhshi², Shapoor Jaberzadeh ${ }^{3}$
}

1. Department of Physical Therapy, University of Social Welfare and Rehabilitation Sciences, Tehran, Iran.

2. Department of Biostatistics, University of Social Welfare and Rehabilitation Sciences, Tehran, Iran.

5. Department of Physiotherapy, Faculty of Medicine, Nursing and Health Sciences, Monash University, Australia.

Cttation: Rostami M, Mosallanezhad Z, Nodehi Moghadam A, Bakhshi E, Jaberzadeh Sh. The Relationship Between Demographic, Health, Physical Fitness and Socioeconomic Determinants and Functional Performance of Elderly People. Physical Treatments. 2016; 6(1):9-18. https://doi.org/10.18869/ NRIP.PTJ.6.1.9

: https://doi.org/10.18869/NRIP.PTJ.6.1.9

Article info:

Received: 02 Sep. 2015

Accepted: 09 Jan. 2016
Keywords:

Elderly, Performance,

Health, Cognition,

Physical fitness, Socio-

economic status

\begin{abstract}
A B S T RA C T
Purpose: Increased life expectancy leads to an increase in the elderly population. However, with an increase in the age, the number of chronic diseases and cognitive disorders also increases. Since the social, cultural, environmental, lifestyle and health-related behavior is specific to each nation, the present study aimed at investigating the relationship between socio-economic status, health, physical fitness, and cognitive function in older adults with functional performance in Iran.
\end{abstract}

Methods: It is a cross-sectional study involving 42 older adults ( 20 women, 22 men) through a survey questionnaire and accessible sampling method. The age range of the study participants was 60 to 91 years. The questionnaire was used by the examiner to collect information on the age, height and weight, history of diseases, health status, physical fitness, and socio-economic status, for assessing the functional performance of older adults. The three performed tests included Sit-toStand test to examine the strength and lower extremity function, the Timed Up and Go (TUG) test to measure the speed and balance while walking and the Purdue Pegboard Test (PPT) for measuring the hand function. A step-wise regression model analysis was applied by using SPSS (version 19).

Results: In sit-to-stand test, the test of significance of regression coefficients was profound in case of dependent variables (marital status $(\mathrm{P}=0.003)$ and overweight $(\mathrm{P}=0.014)$ ). In TUG test, the dependent variables, age $(\mathrm{P}=0.002)$, marital status $(\mathrm{P}=0.081)$, and cognitive function $(\mathrm{P}=0.048)$ were influential on the TUG performance. In PPT, the independent variables, age $(\mathrm{P}=0.041)$, gender $(\mathrm{P}=0.012)$, marital status $(\mathrm{P}=0.058)$, and cognitive function $(\mathrm{P}=0.001)$, had a significant effect on the hand function.

Conclusion: Age-related changes, cognitive functions, and socioeconomic status were the most important factors affecting the functional performance of the elderly. Weight and gender also affected some aspects of functional performance. The author further recommends controlling and preventing loss of cognitive function and improving the social status and age-related changes in the older Iranian adults.

\section{* Corresponding Author:}

Zahra Mosallanezhad, PhD

Address: Department of Physical Therapv, University of Social Welfare and Rehabilitation Sciences, Koodakyar Ave., Daneshjoo Blvd., Evin, Tehran, Iran Phone: +98 (21) 22180039

E-mail:zmosallanezhad@yahoo.com 


\section{Introduction}

1

ging is considered as a quiet and hidden biological process associated with certain degenerative changes in the body structure after maturation, causing a reduction in body functions. Since 1999, the UN Commission on Population and Development has considered the age of sixty as the entering to the elderly age, and those who have passed this age are considered as older adults [1]. Mortality reduction and increased life expectancy have caused an increase in the number of the elderly. In Iran, which is a developing country, based on 2011 census the elderly population has made up to $7 \%$ of the total population.

The predictions indicate a considerable increase of about $20-25 \%$ in elderly population by 2050 [2]. With aging, the incidence of chronic diseases and cognitive disorders also increases. In addition, some degenerative changes have been observed in the motor system, musculoskeletal system, and brain cortex, possessing a significant effect on the motor functioning in the elderly [3]. Performance deficiency and reduction in the quality of life are the problems experienced by $5-20 \%$ of the elderly [4]. For instance, in a study on the performance of the elderly, it was found that the most number of declining in the balance and walking speed occurred from the age of 60 to 70 years [5]. Low-speed walking and decreased physical activity are the major creators of disability, and this reduction or lack of physical activity can be the most important risk factors for the development of morbidity and even mortality [6].

The results of a recent study on the Iranian elderly showed that the performance disorders do have a high contagion, and the life quality and health status creates a dissatisfactory situation [7]. In a study comparing the Iranian and Swedish elderly, it was found that the Iranian elderly have a lower physical health, functional performance, and physical performance as compared to their Swedish counterparts, which justifies the importance of elderly care in Iran [8]. The functional performance include the necessary physical and mental activities for maintaining a healthy life [9] and can be measured with direct and indirect indexes [3].

In this study, to measure the performance capacity of the elderly three tests, such as speed walking and balance, getting up from the chair, and hand function has been used to evaluate the motor functioning of different motion body parts including the upper and the lower limbs. Habits and methods related to the physical ac- tivities of each person are formed during the person's life, and various factors including cultural, social and economic indexes with the social level of the society affect it [10]. Different socioeconomic aspects, such as individual characteristics, urban life, and cultural issues (including perception, tendencies, and behaviors) can affect the health status of every person [11-13]. These dissimilar characteristics of the elderly cause a different rate of disability among the countries worldwide [14].

In this study, the survey questionnaires were used to assess the health status, mental performance, smoking habits, etc., in the elderly, which was self-reported. The survey results were validated are documented as an independent marker for morbidity, mortality, and performance in the elderly [15]. Specific aspects of social, cultural and environmental as well as health-related lifestyle and specific behaviors vary among different nations. The studies conducted in the area of the factors affecting different aspects of the performance in the elderly are mostly related to the western societies, which is very different from the status, lifestyle, beliefs and behaviors, and also some other personal, environmental and social factors in a country such as Iran $[10,11]$. The study aimed at analyzing the relationship between demographic, health, physical fitness and socioeconomic determinants, and functional performance of elderly people.

\section{Materials and Methods}

\section{Participants}

In this cross-sectional study, a sample size of 42 senior citizens consisting of 22 men and 20 women were analyzed. The target population included Iranian elderly with an age range of 60 to 91 years (mean age of $70 \pm 8.8$ years). The samples were chosen in accordance with the convenience sampling method and with the power of $80 \%$ as based on the pre-study.

This study was conducted under the confirmation of the Ethics Committee of Tehran University of Social Welfare and Rehabilitation, in different parts of the city of Tehran in 2015. After receiving the complete data and information about the study conditions, the subjects filled in the satisfaction forms and questionnaires and gave their consent for participation. The inclusion criteria were 60 years of age and above [1], independent older adults who were capable of doing their daily activities with or without assistive devices [16], and mini mental state examination (MMSE) test score more than 23, which was used for detecting the cognitive disorders [17].

If any of the candidates had suffered from any severe musculoskeletal defects, visual and auditory deficiencies, 
balance disorders, and frequent dizziness, which were registered in their medical records or at the time of conducting the study were excluded from the study. According to the opinion of the medical supervisor, these disorders could block the elderly cooperation in the study [18].

\section{Data collection}

\section{Data collection instruments}

The data-collecting questionnaire was used as a study instrument through which the age, height, weight, history of the diseases of various body systems, health status, and physical fitness was determined by the tester and completed in interviews and self- report [8]. The data related to the performance activities was collected through evaluating the elderly people during the test $[8,9]$.

\section{Background information}

The data with relation to age, gender, height, weight, and hand function of the most of the samples were recorded. To measure the weight and height, a scale and a tape meter were used, respectively.

\section{Health status}

The questions were answered in the self-report method. The questions included:

- How do you evaluate your health status? (Very bad, bad, almost good, good, very good),

- Do you feel a general tiredness? (Yes, no), and

- How much do the musculoskeletal problems affect your general health status? (Very much, much, average, little, very little).

And finally, various health problems such as heartvascular system, respiratory system, digestive system, etc. which threaten the one's health were questioned. MMSE test was also used to analyze the individual's psychological health.

\section{Physical fitness status}

The factors like body mass index (BMI), regular work out (yes, no), and physical fitness status (very bad, bad, almost good, good, very good) were recorded by the subjects in the self-report.

\section{Socioeconomic status}

The subjects were asked to report their level of academic education (including under diploma, diploma, BA, MA, MSc., and any higher degrees) and marital status (the elderly ones who were living with their spouse were considered married, and those who have lost their spouse or divorced were considered single).

\section{Smoking/drinking habits}

The subjects were questioned about their smoking or alcohol drinking habits and duration of the habits (at present, it's been five years I have stopped, it's been more than five years I have stopped).

\section{Functional performance}

The elderly in this study were evaluated for their performance activities through the following tests:

\section{Sit to Stand Test}

This test is known as the 30-second-Chair-Stand Test (CST), which analyzes and evaluates the physical performance in the elderly people. The test analyzes the muscle strength around the knee muscle and lower limb in the elderly. The CST test is widely preferred in case of elderly because it is very simple and applicable for elderly with a lot of simple moving problems $[19,20]$. The subject is asked to simultaneously sit down and stand up on a $43 \mathrm{~cm}$ chair for $30 \mathrm{sec}$, and the repetition of the action is calculated [21].

\section{Time Up and Go (TUG) test}

This is a functional test in which the walking speed, balance, and the one's performance are analyzed. It is also considered as a simple and cost effective way that includes daily movements $[22,23]$. This test includes getting up from the $45 \mathrm{~cm}$ chair, walking for $3 \mathrm{~m}$, turning and coming back, and then sitting down on the chair. The time taken by the subject for completion of the process is calculated [23].

\section{Hand performance test}

This test is known as the Purdue Pegboard Test (PPT), which was designed by Joseph Tiffin in 1948 to analyze the hand skill and the coordination between the two hands. This test is capable of analyzing two different features, such as the gross and fine hand movement and fingers. This test includes a board with some holes on it and some small iron bars and two kinds of washer, which are placed in the holes as per the instruction manual [24]. 
Table 1. The effective variables on the chair standing in the elderly.

\begin{tabular}{|c|c|c|c|c|c|}
\hline $\begin{array}{l}\text { Dependent Vari- } \\
\text { able (Criterion) }\end{array}$ & $\begin{array}{l}\text { Independent Variable } \\
\text { (Predictor) }\end{array}$ & $\begin{array}{c}\text { Standard Regression } \\
\text { Coefficient }\end{array}$ & $\begin{array}{c}\text { Non-Standard Regression } \\
\text { Coefficient }\end{array}$ & T-Score & Sig. \\
\hline \multirow{2}{*}{$\begin{array}{l}30 \text { second chair } \\
\text { stand test }\end{array}$} & Overweight & -1.851 & -0.376 & -2.565 & 0.014 \\
\hline & Marital status (the married) & 0.451 & 2.390 & 3.193 & 0.003 \\
\hline
\end{tabular}

PHYSICAL TREA TMENTS

Data analysis was conducted through a step-wise Logistic Regression model, with the use of SPSS version 19.

\section{Results}

\section{Descriptive statistics}

Almost about half of the participants were women $(47.6 \%)$. The mean age of the women and men participating in this study was $79.7 \pm 8.68$ years and $44.9 \pm 9.71$ years, respectively. Sixty-nine percent of the participant lived with their spouses, and $31 \%$ of them have lost their spouses or were divorced. Twentythree of the total participants $(54.7 \%)$ were overweight $(B M I \geq 25)$. The MMSE mean score in the study was $27.9 \pm 1(23 \leq \mathrm{MMSE} \geq 30)$. Only $23 \%$ of the elderly had a regular exercise program, and exactly the same percentage of participants felt general tiredness. Fifty percent of the total elderly people reported good health status, and $47.7 \%$ of them reported almost good health status. Whereas the physical fitness status of $50 \%$ elderly was almost good, for $43 \%$ it was good, and for $7 \%$ it was very good.

\section{Regression analysis}

For each of the performance tests, a separate regression model was evaluated. In each of the models, one of the performance tests (Chair Sand Test, walking and balance speed test or hand performance test) was considered as the dependent variable, and the collection of the background variables, variables related to the health status, physical fitness, and socioeconomic status were chosen as the independent variables in the study.

\section{Chair Stand Test (CST)}

The regression coefficient and the level of the significance related to the effects of the dependent and independent variables in the Chair Stand Test showed that the variables of marital status $(\mathrm{P}=0.003)$ and overweight $(0.014)$ had a significant influence on the performance of standing P-value from the chair (Table 1). The results showed that in the case of overweight elderly, the proportion specific to CST was 1.85 lower than the elderly with normal weight. In the elderly who lived with their spouses, the amount of CST was 2.93, which was more than those who lived alone.

\section{Timed Up and Go Test}

The analysis of regression coefficient and the level of the significance in relation to the effects of the independent variables on the independent variable of the speed and the balance of walking showed that the variables of age $(\mathrm{P}=0.002)$, marital status $(\mathrm{P}=0.081)$, and cognitive status $(\mathrm{P}=0.048)$ had a significant influence on TUG (Table 2). The results showed that:

- With the increase in the age, the time taken by the elderly for completion of the TUG test increased by 0.27 , and

- With the increase of MMSE score, the time of the TUG test is reduced by 0.90 .

In the elderly who lived with their spouses, the time of performing the TUG was 2.92 credits less than those who lived alone.

Table 2. The effective variables on the speed and the balance of the elderly more than 60 years old.

\begin{tabular}{cccccc}
\hline $\begin{array}{c}\text { Dependent Variable } \\
\text { (Criterion) }\end{array}$ & $\begin{array}{c}\text { Independent Variable } \\
\text { (Predictor) }\end{array}$ & $\begin{array}{c}\text { Standard Regression } \\
\text { Coefficient }\end{array}$ & $\begin{array}{c}\text { Non-standard Regres- } \\
\text { sion Coefficient }\end{array}$ & T-Score & Sig. \\
\hline \multirow{3}{*}{ Timed up and go } & Age & 0.472 & 0.269 & 3.384 & 0.002 \\
& MMSE & -0.307 & -0.896 & -2.041 & 0.048 \\
\hline & Marital status (married) & -0.272 & -2.924 & -1.791 & 0.081 \\
\hline
\end{tabular}


Table 3. The effective variables on hand performance in the elderly population of more than 60 years old.

\begin{tabular}{|c|c|c|c|c|c|}
\hline $\begin{array}{l}\text { Dependent Variable } \\
\text { (Criterion) }\end{array}$ & $\begin{array}{l}\text { Independent Variable } \\
\text { (Predictor) }\end{array}$ & $\begin{array}{c}\text { Standard Regression } \\
\text { Coefficient }\end{array}$ & $\begin{array}{l}\text { Non-Standard Regres- } \\
\text { sion Coefficient }\end{array}$ & T-Score & Sig \\
\hline \multirow{4}{*}{ Purdue Pegboard Test } & Age & -0.317 & -0.237 & -2.111 & 0.041 \\
\hline & Gender (men) & -0.385 & -5.032 & -2.641 & 0.012 \\
\hline & MMSE* & 0.489 & 1.876 & 3.550 & 0.001 \\
\hline & Marital status (married) & 0.294 & 4.154 & 1.949 & 0.058 \\
\hline
\end{tabular}

\section{Hand Performance Test}

The analysis of regression coefficient and the level of the significance in relation to the independent variables on the independent variables of hand performance showed that the variables of age $(\mathrm{P}=0.041)$, gender $(\mathrm{P}=0.012)$, marital status $(\mathrm{P}=0.058)$, and cognitive status $(\mathrm{P}=0.001)$ had a significant influence on the hand performance (Table 3). The results showed that:

- With increasing age, the PPT level decreased by 0.237 ,

- In the case of women subjects, the PPT score was more than 5.032 as compared to the male counterpart,

- With each unit increase in the MMSE score, the amount of PPT is increased to size 1.88 , and

- Elderly who lived with their spouses, the PPT was 4.15 more than the elderly who lived alone.

\section{Discussion}

\section{Overview of the results}

The overall results showed that marital status and overweight were the factors affecting the chair stand test, whereas the factors affecting the Timed Up and Go test were age, marital status, and the MMSE test score. In addition, the factors affecting hand performance were age, gender, MMSE test score, and marital status.

\section{Chair Stand Test}

Based on our findings, the married elderly with lower weight could perform the chair stand test better. However, the overweight factor in the elderly can hasten the declining physical performance. This Age related process can cause weakness and morbidity and reduction in the quality of life in the elderly performances $[25,26]$. Many factors from the physiologic and cognitive aspects are related to the chair stand test. Hence, this test is not considered as the sole indicator of the power in the lower limbs.

In a study by Lord et al. (2002), the performing chair stand test in addition to knee flexor muscle highlighted the other important factors, such as body weight, pain, anxiety and worries, depression, mood, and other sensory-motor processes. Body weight, as an independent indicator, indicates that lifting and lowering a body with high weight requires more energy and work. On the other hand, the elderly performance in this study was not dependent on the height, gender, and age, which could be in the same way as suggested by our results.

The participants' motivation and perception along with the three other factors of anxiety, pain, and vitality are the influencing psychological factors in this test [27], which can be related to the marital status of the elderly. This refers to those who live with their spouses and are presented with less anxiety level, better physical performance, and more satisfaction in life [28]. In a study by Kaplan et al. (1993), they could not find any significant relationship between the weight and activities of daily living, functional performance and mobility of elderly subjects. [29]. But in this study, it was shown that there is a significant correlation between being married and physical performance in the elderly. Those who live with their spouse showed a higher physical performance [29]. In our study, gender did not influence the performance, but in the study by Cardoso et al. (2013), it was seen that men did show a lower performance [30].

TUG test is used to evaluate the performance of the lower limb and components such as speed and balance. The results of this study indicated that the physical performance is influenced by variables, such as age, marital status, and cognitive status of the subjects. In a previous study, it was observed that there was no difference between balance and walking characteristics between both the genders, which means the range and the age of starting disorders in men and women are the same. However, in lower age, balance problems are associated with more disorders in comparison to the walking speed [5]. 
Many studies have reported that the walking speed and balance decrease with aging [31-34]. Balance, walking speed, and mobility start decreasing from 40 to 60 years old [31, 34-36]. TUG test is a disability-indicating test. It is said that walking speed is related to the disability $[6,37,38]$. In a study by Samson et al. (2001), the results indicated that walking speed decreases with aging, but weight does not have any specific effects on walking speed, which is in the same line with the results of the present study [39]. In a study by Rosano et al. (2004), it was shown that there was a statistically significant relationship between the physical performance and cognitive performance. In this study, they used Teng-modified MMSE to evaluate the cognitive status of the elderly, which included the characteristics of the MMSE test. The results of this study supported the hypothesis that lower walking speed can be indicative of the weaker cognitive performance, which is in the same line with the present study results [40].

Among other findings of the present study, hand performance in both the genders was seen to decrease with aging. In fact, the more is the age, less is the PPT score [41]. The greater decrease was seen in elderly after the age of 65 years. The worse hand performance in the elderly is mostly related to the second and degenerative changes in the musculoskeletal, cardiovascular, and nervous system [42]. MMSE is one of the most applied methods for evaluating the cognitive disorders in the elderly [43]. Leveille et al. (1998) stated a clear relationship between the MMSE low scores and difficulty in performing daily activities [44].

In another study by Weuve et al. (2004), it was observed that those who have a high level of activity possessed better cognitive performances. And the cognitively active people showed less decrease in their performance [45]. As it is seen in the present study, in both the hand and walking speed tests, two variables of age and MMSE were influential. This was confirmed by other studies in which the MMSE score test decreased with aging, and this decrease intended towards more speed in elderly more than 70 years old $[46,47]$. Marital status had significant relationship with other three performance tests. One of the reasons can be the effect of being married on the quality of life in aged population. Among other possibilities, it can be referred to the fact that some other tests are not just related to the muscle power and some psychological factors are also involved in determining the quality of performing these tests [27]

In a study by Kaplan (1993), the results indicated a relationship between marital status and physical performance in the elderly [48]. The quality of life of the married elderly is of high level, and separated or divorced elderly have the least amount of life quality. Quality of life includes different aspects, such as physical performance, self-care, life satisfaction, depression, and anxiety [28, 49]. These findings are in the same line with the present study.

One the variables affecting hand performance is the gender, and this variable has been only observed in PPT in which used for determining the hand performance level. Senior women in comparison to their men counterparts showed a better performance. Gender differences in upper limbs performance are dissimilar in the studies. In the studies dealing with healthy samples, and PPT has been used as a test, and the results indicated that women's performance was much better than the men [24, 41].

In a comparative study which was among the elderly people in Iran and Sweden, it was observed that the level of physical activity in senior women was more than the men, which was opposite of the findings in Sweden [8]. In another study by Hackel et al. (1992), they used Jebsen test to evaluate hand performance. Based on the results, gender had a slight effect on the hand performance, but in some parts of the test, women performed better and faster than men [50]. On the other hand, in a study by Smith et al. (1999), which was about the slight hand movement of the elderly, the results showed no difference between both the genders [51]. In another study, the mean score of PPT for senior men was 8.20, and for women, it was 3.20, which was the opposite of the findings of this study [52]. Hence, it can be concluded that the women doing simple hand performance showed better performance than the men [53].

The present findings indicate a significant effect of the marital status, age, cognitive status of the elderly, gender, and also the weight of the elderly on different parts of the body performance, such as upper and lower limbs.

The most important and significant limitation of this study was the smaller sample size of the target population who were analyzed. Hence, the deduced findings might not be a generalized indicator for the total elderly population. Such limitation can be overcome by random sampling among the elderly in the society, and a larger sample size needs to be studied for better generalization of the outcomes.

\section{Application}

The findings of the present study can provide useful information to recognize the effective of various factors 
on the performance of the elderly and suggest effective ways to apply to their performance in the area of rehabilitation, such as improving the cognitive status of the elderly and reducing the mental pressure on them and their loneliness.

\section{Acknowledgements}

This paper had no financial supporters. We highly appreciate the elderly people who have given their consent for participation and have collaborated in this study. .

\section{Conflict of Interest}

The authors declared no conflict of interests.

\section{References}

[1] Kanaani MO, Hosseini SJ. [Explosion of the elderly and their health needs: Iran's assets and needs until 1430 (Persian)]. Paper presented at: The Congress on Analysis of Population Trends; 2000 June 24-25; Tehran, Iran.

[2] Statical Center of Iran. [Iran Statistical Yearbook (Persian)] [Internet]. 2012 [Cited 2012 July 12]. Available from: www. amar.org.ir/Default.aspx

[3] Danielewicz AL, Barbosa AR, del Duca GF. Nutritional status, physical performance and functional capacity in an elderly population in Southern Brazil. Revista da Associação Médica Brasileira. 2014; 60(3):242-48. doi: 10.1590/18069282.60.03.0013

[4] Akbari KA, Azadi F, Salavati M, Kazemi B. [Prediction of risk of falling among institutionalized elderly people in Iran (Persian)]. Journal of Rehabilitation. 2003; 13(4):45-51.

[5] Daly RM, Rosengren BE, Alwis G, Ahlborg HG, Sernbo I, Karlsson MK. Gender specific age-related changes in bone density, muscle strength and functional performance in the elderly: A 10 year prospective population-based study. BMC Geriatrics. 2013; 13(1):1. doi: 10.1186/1471-2318-13-71

[6] Gobbens RJ, van Assen MA. The prediction of ADL and IADL disability using six physical indicators of frailty: A longitudinal study in the Netherlands. Current Gerontology and Geriatrics Research. 2014; 2014. doi: 10.1155/2014/358137

[7] Tajvar M, Arab M, Montazeri A. Determinants of healthrelated quality of life in elderly in Tehran, Iran. BMC Public Health. 2008; 8(1):1. doi: 10.1186/1471-2458-8-323

[8] Mosallanezhad Z, Hörder H, Salavati M, Nilsson-Wikmar L, Frändin K. Physical activity and physical functioning in Swedish and Iranian 75-year-olds: A comparison. Archives of Gerontology \& Geriatrics. 2012; 55(2):422-30. doi: 10.1016/j.archger.2012.02.007

[9] Verbrugge LM, Jette AM. The disablement process. Social Science \& Medicine. 1994; 38(1):1-14. doi: 10.1016/02779536(94)90294-1
[10] Watt HC, Carson C, Lawlor DA, Patel R, Ebrahim S. Influence of life course socioeconomic position on older women's health behaviors: findings from the British women's heart and health study. American Journal of Public Health. 2009; 99(2):320-27. doi: 10.2105/ajph.2007.129288

[11] Dragano N, Bobak M, Wege N, Peasey A, Verde PE Kubinova R, et al. Neighbourhood socioeconomic status and cardiovascular risk factors: A multilevel analysis of nine cities in the Czech Republic and Germany. BMC Public Health. 2007; 7(1):1. doi: 10.1186/1471-2458-7-255

[12] Hillsdon M, Lawlor D, Ebrahim S, Morris J. Physical activity in older women: Associations with area deprivation and with socioeconomic position over the life course: Observations in the British Women's heart and health study. Journal of Epidemiology \& Community Health. 2008; 62(4):344-50. doi: $10.1136 /$ jech. 2006.058610

[13] Elovainio M, Kivimäki M, Kortteinen M, Tuomikoski H. Socioeconomic status, hostility and health. Personality \& Individual Differences. 2001; 31(3):303-15. doi: 10.1016/s01918869(00)00137-9

[14] Manton KG. Recent declines in chronic disability in the elderly US population: Risk factors and future dynamics. Annual Review of Public Health. 2008; 29:91-113. doi: 10.1146/ annurev.publhealth.29.020907.090812

[15] Lee Y. The predictive value of self assessed general, physical, and mental health on functional decline and mortality in older adults. Journal of Epidemiology \& Community Health. 2000; 54(2):123-29. doi: 10.1136/jech.54.2.123

[16] Mosallanezhad Z, Salavati M, Hellström K, Reza Sotoudeh G, Nilsson Wikmar L, Frändin K. Cross-cultural adaptation, reliability and validity of the Persian version of the Modified Falls Efficacy Scale. Disability \& Rehabilitation. 2011; 33(2526):2446-53. doi: 10.3109/09638288.2011.574774

[17] Foroughan M, Jafari Z, Shirin BP, Ghaem MFZ, Rahgozar M. [Validation of mini-mental state examination (MMSE) in the elderly population of Tehran (Persian)]. Advances in Cognitive Science. 2008; 10(2):29-37.

[18] Bayatloo A, Salavati M, Akhbari B. [The ability to selectively allocateattentional demands on walking during secondary cognitive and motor tasks in elderly people with and without a history of falls (Persian)]. Iranian Journal of Ageing. 2011; 5(4):14-20.

[19] Nakazono T, Kamide N, Ando M. The reference values for the chair stand test in healthy Japanese older people: determination by meta-analysis. Journal of Physical Therapy Science. 2014; 26(11):1729-731. PMID: 25435687.

[20] Jones C], Rikli RE, Beam WC. A 30-s chair-stand test as a measure of lower body strength in community-residing older adults. Research Quarterly for Exercise \& Sport. 1999; 70(2):113-39. doi: 10.1080/02701367.1999.10608028

[21] Rikli RE, Jones CJ. Functional fitness normative scores for community residing older adults ages 60-94. Journal of Aging \& Physical Activity. 1999; 7:162-81. doi:10.1123/ japa.7.2.162

[22] Nordin E, Rosendahl E, Lundin-Olsson L. Timed "Up \& Go" Test: Reliability in older people dependent in activities of daily living-focus on cognitive state. Physical Therapy. 2006; 86(5):646-55. PMID: 16649889 
[23] Podsiadlo D, Richardson S. The timed "Up \& Go": A test of basic functional mobility for frail elderly persons. Journal of the American Geriatrics Society. 1991; 39(2):142-48. doi: 10.1111/j.1532-5415.1991.tb01616.x

[24] Tiffin J, Asher EJ. The Purdue Pegboard: Norms and studies of reliability and validity. Journal of Applied Psychology. 1948; 32(3):234-47. PMID: 18867059

[25] Villareal DT, Banks M, Siener C, Sinacore DR, Klein S. Physical frailty and body composition in obese elderly men and women. Obesity Research. 2004; 12(6):913-20. doi: 10.1038/ oby.2004.111

[26] Blaum CS, Xue QL, Michelon E, Semba RD, Fried LP. The association between obesity and the frailty syndrome in older women: The women's health and aging studies. Journal of the American Geriatrics Society. 2005; 53(6):927-34. doi: 10.1111/j.1532-5415.2005.53300.x

[27] Lord SR, Murray SM, Chapman K, Munro B, Tiedemann A. Sit-to-stand performance depends on sensation, speed, balance, and psychological status in addition to strength in older people. The Journals of Gerontology Series A: Biological Sciences \& Medical Sciences. 2002; 57(8):539-43. doi: 10.1093/gerona/57.8.m539

[28] Bazrafshan MR, Hosseini M, Rahgozar M, Sadat Madah B. [Quality of elderly's life in Shiraz, Jahandidegan Club (Persian)]. Iranian Journal of Ageing. 2008; 3(1):33-41.

[29] Kaplan GA, Strawbridge WJ, Camacho T, Cohen RD. Factors associated with change in physical functioning in the elderly a six-year prospective study. Journal of Ageing \& Health. 1993; 5(1):140-53. doi: 10.1177/089826439300500107

[30] Cardoso AF, Barbosa AR, Coqueiro RDS. Musclestrength in the oldest old and associated factors. Revista Brasileira de Ciências do Esporte. 2013; 35(4):963-81. doi: 10.1590/s010132892013000400011

[31] el Haber N, Erbas B, Hill KD, Wark JD. Relationship between age and measures of balance, strength and gait: Linear and non-linear analysis. Clinical Science. 2008; 114(12):71927. doi: $10.1042 / \operatorname{cs} 20070301$

[32] Studenski S, Perera S, Patel K, Rosano C, Faulkner K, Inzitari $\mathrm{M}$, et al. Gait speed and survival in older adults. JAMA. 2011; 305(1):50-58. doi: 10.1001/jama.2010.1923

[33] Era P, Sainio P, Koskinen S, Haavisto P, Vaara M, Aromaa A. Postural balance in a random sample of 7.979 subjects aged 30 years and over. Gerontology. 2006; 52(4):204-13. doi: $10.1159 / 000093652$

[34] Shumway-Cook A, Guralnik JM, Phillips CL, Coppin AK, Ciol MA, Bandinelli S, et al. Age-Associated declines in complex walking task performance: The walking in CHIANTI toolkit. Journal of the American Geriatrics Society. 2007; 55(1):58-65. doi: 10.1111/j.1532-5415.2006.00962.x

[35] Isles RC, Choy NL, Steer M, Nitz JC. Normal values of balance tests in women aged 20-80. Journal of the American Geriatrics Society. 2004; 52(8):1367-72. doi: 10.1111/j.15325415.2004.52370.x

[36] Choy NL, Brauer S, Nitz J. Changes in postural stability in women aged 20 to 80 years. The Journals of Gerontology Series A: Biological Sciences \& Medical Sciences. 2003; 58(6):525-30. doi: 10.1093/gerona/58.6.m525
[37] Rothman MD, Leo-Summers L, Gill TM. Prognostic significance of potential frailty criteria. Journal of the American Geriatrics Society. 2008; 56(12):2211-216. doi: 10.1111/j.15325415.2008.02008.x

[38] van Kan GA, Rolland Y, Andrieu S, Bauer J, Beauchet O, Bonnefoy M, et al. Gait speed at usual pace as a predictor of adverse outcomes in community-dwelling older people an International Academy on Nutrition and Aging (IANA) task force. Journal of Nutrition, Health \& Ageing. 2009; 13(10):881-89. doi: 10.1007/s12603-009-0246-Z

[39] Samson M, Crowe A, De Vreede P, Dessens J, Duursma $\mathrm{S}$, Verhaar $\mathrm{H}$. Differences in gait parameters at a preferred walking speed in healthy subjects due to age, height and body weight. Aging Clinical \& Experimental Research. 2001; 13(1):16-21. doi: 10.1007/bf03351489

[40] Rosano C, Simonsick EM, Harris TB, Kritchevsky SB, Brach $\mathrm{J}$, Visser M, et al. Association between physical and cognitive functionin healthy elderly: The health, aging and body composition study. Neuroepidemiology. 2004; 24(1-2):8-14. doi: $10.1159 / 000081043$

[41] Desrosiers J, Hebert R, Bravo G, Dutil E. The Purdue Pegboard Test: Normative data for people aged 60 and over. Disability \& Rehabilitation. 1995; 17(5):217-24. doi: $10.3109 / 09638289509166638$

[42] Carmeli E, Patish H, Coleman R. The aging hand. The Journals of Gerontology Series A: Biological Sciences \& Medical Sciences. 2003; 58(2):146-52. doi: 10.1093/gerona/58.2.m146

[43] Folstein MF, Folstein SE, McHugh PR. Mini-mental state: a practical method for grading the cognitive state of patients for the clinician. Journal of Psychiatric Research. 1975; 12(3):18998. doi: 10.1002/(sici)1099-1166(199805)13:5<285::aid-gps753 $>3.3 . \mathrm{co} ; 2-\mathrm{m}$

[44] Leveille SG, Guralnik JM, Ferrucci L, Corti MC, Kasper J, Fried LP. Black/white differences in the relationship between MMSE scores and disability: The women's health and aging study. The Journals of Gerontology Series B: Psychological Sciences \& Social Sciences. 1998; 53(3):201-08. doi: 10.1093/geronb/53b.3.p201

[45] Weuve J, Kang JH, Manson JE, Breteler MM, Ware JH, Grodstein F. Physical activity, including walking, and cognitive function in older women. JAMA. 2004; 292(12):1454-61. doi: 10.1001/jama.292.12.1454

[46] Schaie KW. Longitudinal studies of adult psychological development. New York: Guilford Press; 1983.

[47] Butler SM, Ashford JW, Snowdon DA. Age, education, and changes in the Mini-Mental State Exam scores of older women: Findings from the Nun Study. Journal of the American Geriatrics Society. 1996; 44(6):675-81. doi: 10.1111/j.15325415.1996.tb01831.x

[48] Wray LA, Blaum CS. Explaining the role of sex on disability; A population-based study. Gerontologist. 2001; 41(4):499510. doi: 10.1093/geront/41.4.499

[49] Alipoor F, Sajjadi H, Foroozan A, Biglarian A, Jalilian A. [Quality of life in the elderly of district 2, Tehran (Persian)]. 2008; 3(3-4):75-83.

[50] Hackel ME, Wolfe GA, Bang SM, Canfield JS. Changes in hand function in the aging adult as determined by the Jebsen 
Test of hand function. Physical Therapy. 1992; 72(5):373-77. PMID: 1631206

[51] Smith CD, Umberger G, Manning E, Slevin J, Wekstein D, Schmitt $\mathrm{F}$, et al. Critical decline in fine motor hand movements in human aging. Neurology. 1999; 53(7):1458-461. PMID: 10534251

[52] Schroll M, Bjørnsbo-Scroll K, Ferrt N, Livingstone M. Health and physical performance of elderly Europeans. SENECA Investigators. European Journal of Clinical Nutrition. 1996; 50(2):105-11. PubMed: 8841790

[53] Michimata A, Kondo T, Suzukamo Y, Chiba M, Izumi SI The manual function test: norms for 20- to 90-year-olds and effects of age, gender, and hand dominance on dexterity. The Tohoku Journal of Experimental Medicine. 2008; 214(3):257-67. doi: 10.1620/tjem.214.257 
- 